\title{
Correction to: Habitat selectivity of fresh water fishes of two second-order tropical streams in Tigray, Northern Ethiopia
}

Solomon Tesfay*, Mekonen Teferi and Haileselasie Hadush Tsegazeabe

\section{Correction to: J Ecol Environ \\ https://doi.org/10.1186/s41610-019-0107-6}

Following publication of the original article (Tesfay et al., 2019), it was reported that in the Background section, paragraph 4, the word "habitat presences" should be "habitat preferences". The sentence should read: "In addition, we tried to study the quantitative measures of microhabitat use and factors associated with the fish habitat preferences and the streams nature."

Additionally, Fig. 1 was not correctly processed. The correct figure is given below.

Please note that the in-text reference to Fig. $2 b$ should be replaced with Fig. 3 .

The original article (Tesfay et al., 2019) has been corrected.

Received: 2 April 2019 Accepted: 2 April 2019

Published online: 26 April 2019

\section{Reference}

Tesfay, et al. Habitat selectivity of fresh water fishes of two second-order tropical

streams in Tigray, Northern Ethiopia. Journal of Ecology and Environment.

2019;43:9 https://doi.org/10.1186/s41610-019-0107-6.

\footnotetext{
* Correspondence: solomon232000@yahoo.com

Mekelle University, PO Box 231, Mekelle, Tigray, Ethiopia
} 


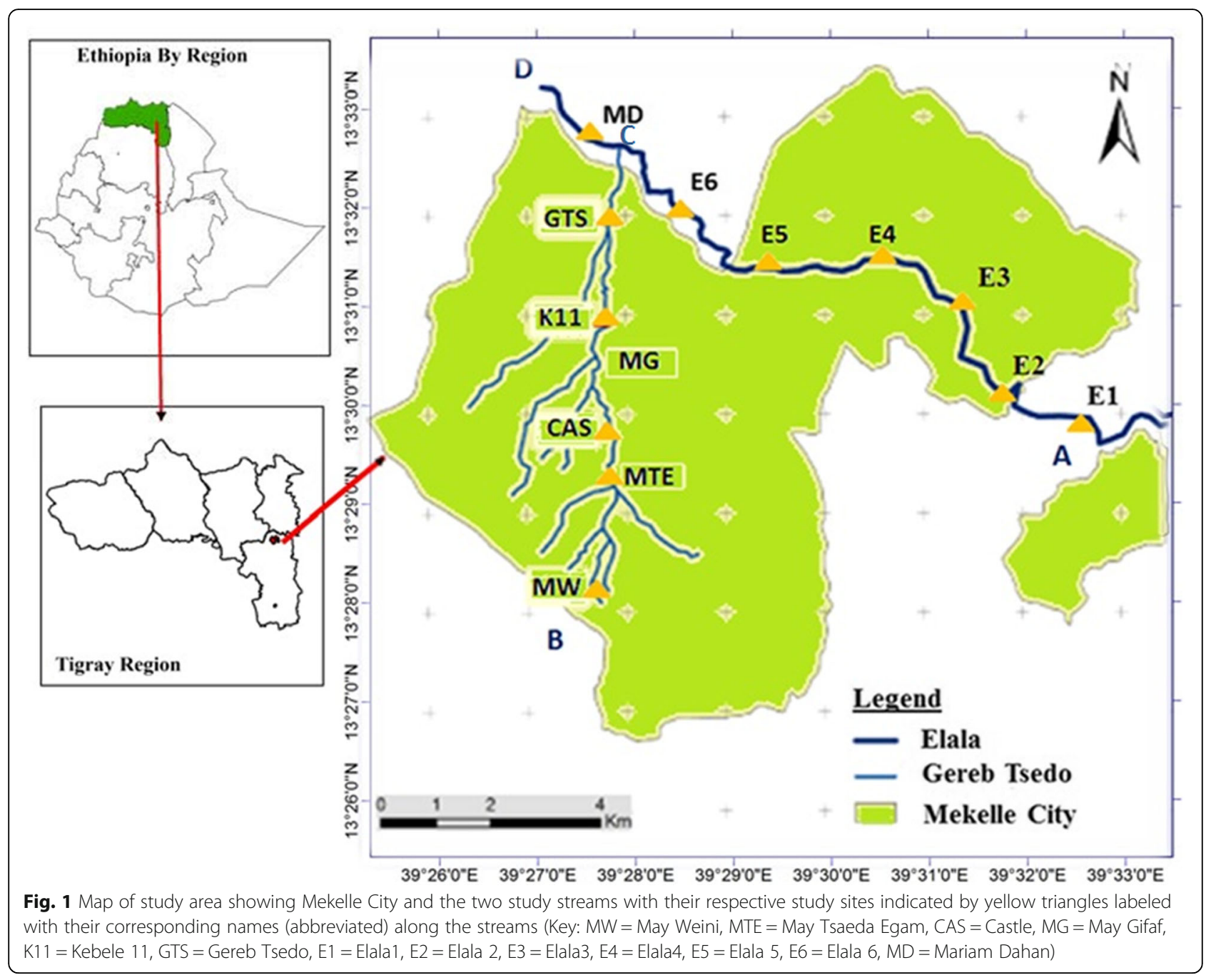

